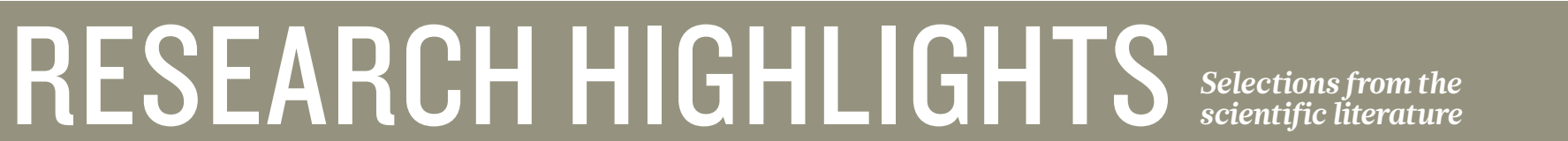

NEUROSCIENCE

\section{Signals activate dormant stem cells}

Dormant stem cells - and the signals that activate them are widespread across surfaces in adult mouse brains.

Yi Eve Sun and Siguang Li of Tongji University School of Medicine in Shanghai, China, and their colleagues analysed patterns of gene expression in individual cells from some regions of the adult mouse brain, looking for patterns that are characteristic of stem cells. They found resting stem cells lining the surfaces of cavities where cerebrospinal fluid is made, and lining the central canal of the spinal cord. Genenetwork analysis revealed that these stem cells could be activated by molecules that are released in response to injury.

When treated with such triggers, the cells in the animal began to develop into neurons, which suggests that their function is to repair neural damage.

Cell http://doi.org/4sk (2015)

\section{PALAEOCLIMATOLOGY}

\section{A breath of ancient air}

One-million-year-old air extracted from bubbles in an Antarctic ice core has enabled the reconstruction of the oldest atmospheric compositions yet studied.

Glaciers flowing over raised bedrock in Allan Hills, Antarctica, brought longsought-after blue ice near to the surface, providing an accessible source of ancient air. John Higgins at Princeton University in New Jersey and his team measured, among other gases, the carbon dioxide and methane content of this trapped air. The findings indicate that the strong

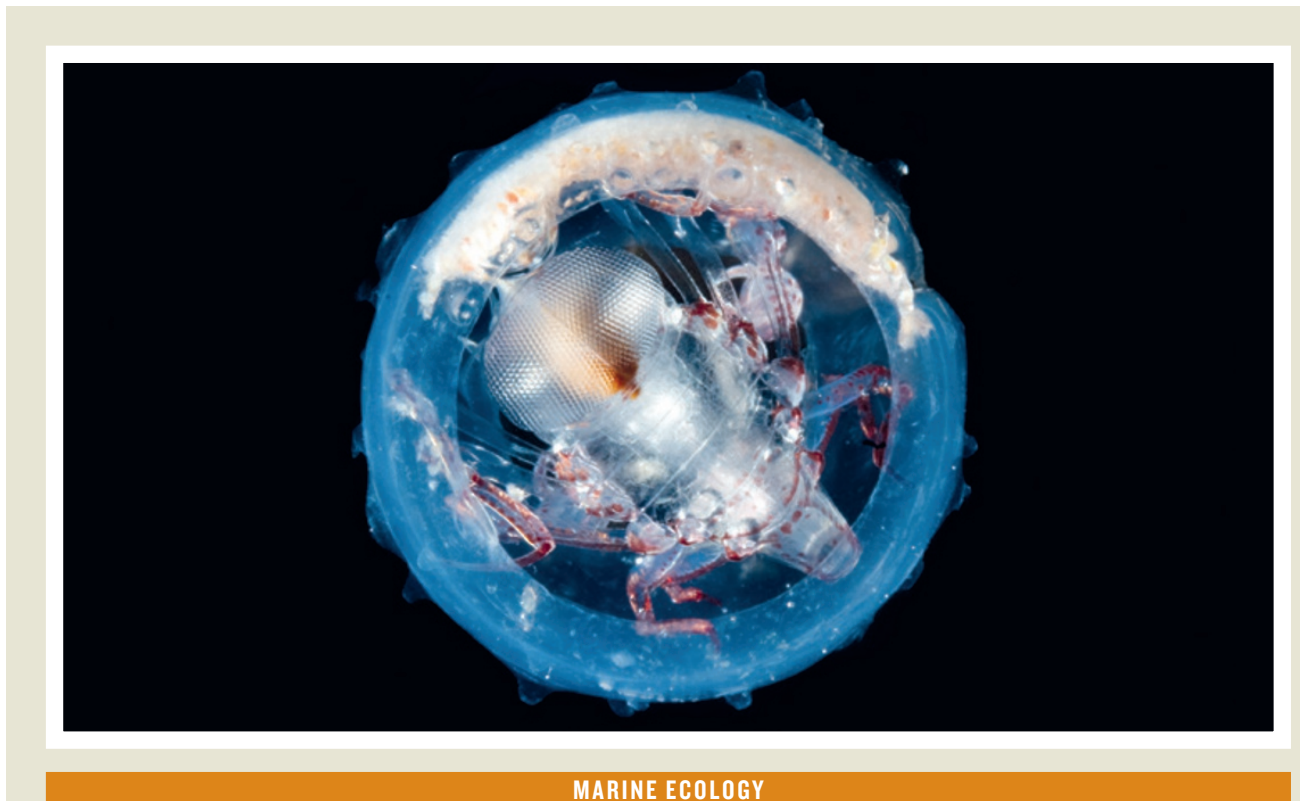

\section{Ocean survey finds huge diversity}

After a 3.5-year voyage at sea, scientists have discovered more than 100,000 new eukaryotic organisms, many existing in symbiotic relationships with each other.

Scientists aboard the research schooner Tara collected some 35,000 ocean samples at 210 locations around the world, from as deep as 2,000 metres below the surface. The team, led by Eric Karsenti at the European Molecular Biology Laboratory in Heidelberg, Germany, made environmental measurements and sequenced and analysed DNA fragments from the samples, looking for new viruses and organisms as big as fish larvae. They found 150,000 genetically distinct kinds of eukaryote (a Phronima crustacean is pictured), many of them singlecelled organisms - and many more than the 11,000 previously known species of marine eukaryotic plankton. They also discovered more than 5,000 genetic populations of viruses, only 39 of which are similar to known viruses.

Temperature seemed to be the environmental factor with the strongest effect on microbial community structure in the upper oceans. The data could be fed into ocean models to predict how these communities might respond to global warming, the authors say.

Science 348, 873 (2015) link between atmospheric greenhouse gases and the Antarctic climate observed for the past 800,000 years extended to at least one million years ago.

Proc. Natl Acad. Sci. USA http://doi.org/4rs (2015)

\section{CANCER BIOLOGY}

\section{Cancer-cell transfer filmed}

High-resolution microscopes have captured images of cancer cells transferring biological material to less-malignant cells, making these cells more cancerous.

Many cells, including cancerous ones, shed tiny membrane-bound sacs called vesicles that contain a variety of molecules including RNA; these sacs are then taken up by other cells. Jacco van Rheenen at the Hubrecht Institute in Utrecht, the Netherlands, and his co-workers imaged human breast-cancer cells in real time in live mice. They found that these cells release vesicles carrying messenger RNA transcribed from genes involved in cell migration and metastasis. After engulfing these vesicles, human cells that were less malignant began to migrate faster than those that did not take up the vesicles. The transferred genetic material also boosted the ability of the cells to spread to other organs.

This vesicle transfer occurred within the same tumour and also between distant ones. Cell http://doi.org/4sj (2015) 